\title{
DETECTION OF MUTATIONS IN THE CYP21A2 GENE: GENOTYPE-PHENOTYPE CORRELATION IN SLOVENIAN COUPLES WITH CONCEIVING PROBLEMS
}

\author{
Stangler Herodež $\breve{S}^{1, *}$, Fijavž L ${ }^{2}$, Zagradišnik B ${ }^{1}$, Kokalj Vokač N ${ }^{1,2}$
}

\begin{abstract}
*Corresponding Author: Dr. Špela Stangler Herodež, Laboratory of Medical Genetics, University Clinical Centre Maribor, Ljubljanska ulica 5, 2000 Maribor, Slovenia. Tel: +386-2-321-27-37. Fax: +386-2-321-27-55. E-mail: spela.sh@ukc-mb.si
\end{abstract}

\begin{abstract}
The objective of this study was to compare the CYP 21A2 genetic profiles of couples with unexplained fertility problems (UFP) with genetic profiles of healthy controls (HCs). Furthermore, we analyzed associations between mutations in the $C Y P 21 A 2$ gene and various clinical and laboratory parameters. Allele-specific polymerase chain reaction (PCR) was used in 638 probands with UFP and 200 HCs. Statistic analysis with $\chi^{2}$ was used to study the association of mutations with infertility. The effect of mutations on particular clinical and laboratory parameters was assessed with the analysis of variance (ANOVA) test. With regard to the $C Y P 21 A 2$ gene, $0.6 \%$ of probands with UFP and $0.5 \%$ of $\mathrm{HCs}$ were positive for the c. $290-13 \mathrm{~A} / \mathrm{C}>\mathrm{G}$ mutation; $0.6 \%$ of probands with UFP and $1.5 \%$ of HCs were positive for the p.I172N mutation; there were no probands with UFP positive for the p.P30L mutation, whereas $0.5 \%$ of $\mathrm{HCs}$ were; and $0.2 \%$ of probands with UFP and $0.5 \%$ of HCs were found to have the p.V281L mutation. We found a significant association between c.290$13 \mathrm{~A} / \mathrm{C}>\mathrm{G}$ mutation and the frequency of significant hormone deviations $\left(\chi^{2}=6.997, p=0.008\right)$. Similar association was also observed between the c.290$13 \mathrm{~A} / \mathrm{C}>\mathrm{G}$ mutation and the frequency of polycystic ovary syndrome $(\mathrm{PCOS})\left(\chi^{2}=16.775, p=0.000\right)$. Our findings indicate that no significant difference

\footnotetext{
${ }^{1}$ Laboratory of Medical Genetics, University Clinical Centre Maribor, Maribor, Slovenia

${ }^{2}$ Medical Faculty, University of Maribor, Maribor, Slovenia
}

in the prevalence of CYP 21A2 mutations can be found in probands with UFP when compared with HCs without infertility history. The results also imply the significant association of the c.290-13A/C $>\mathrm{G}$ mutation in the CYP21A2 gene, not only with the frequency of PCOS, but also with the frequency of significant hormone deviations.

Keywords: CYP21A2 gene; genetics; infertility; mutations; unexplained infertility problems (UFP); healthy controls (HCs).

\section{INTRODUCTION}

The World Health Organization (WHO) estimates that $10.0-15.0 \%$ of couples in the Western World develop issues regarding fertility. In addition, we can estimate that nearly $50.0 \%$ of couples with infertility have an underlying genetic abnormality [1].

Mutation in the CYP21A2 gene results in a defficient 21-hydroxilase (21-OH) enzyme, which in turn leads to diminished aldosterone and cortysole production. Contrarily, the production of testosterone and dihydrotestosterone increases $[2,3]$. Congenital adrenal hyperplasia is a hereditary autosomal recessive disease. A defective 21-OH enzyme is responsible for $90.0 \%$ of disrupted steroid hormone production. The 21-OH catalyzes the conversion of progesterone and 17-hydroxyprogesterone (17-OHP) into 11-deoxycorticosterone (11-DOC) and 11-deoxycortisol. The enzyme is coded by the CYP21A2 gene at position 6 p21.3 [1,4]. Genes involved in steroidogenesis usually comprise 7 to 9 exons but the CYP21A2 gene has 10 
exons. In humans, there are two genes associated with coding $21-\mathrm{OH}$, both located on $6 \mathrm{p} 21.3$, on a region $35 \mathrm{~kb}$ in length in the major histocompatibility complex. The first of two is a disfunctional pseudogene (CYP21A1 or $C Y P 21 P$ ), the second is a functional gene (CYP21A2 or CYP21). The pseudogene encodes an enzyme, nonfunctional due to the frameshift and occurence of a premature stop codon [5].

Although we cannot establish the phenotype only from the genetic profile, there are certain associations between the two. Patients with a detected mutation in the CYP21A2 gene are divided into groups by the severity of the mutation on $21-\mathrm{OH}$ [6]. Clinical findings associated with the phenotype are not always proportional to the degree of disfunction of 21-OH. We assume there are other genes involved in the manifestation of symptoms. There is marked concordance between genotype and phenotype in patients with mild or severe manifestation of congenital adrenal hyperplasia (CAH) [7,8]. Nevertheless, the most common manifestations are virilizing effects, clinically evident as hirsutism or androgenic alopecia. Oligomenorrhea or amenorrhea and ultrasound-evident polycystic ovaries may also be present $[2,9,10]$.

Reduced fertility in female patients with $\mathrm{CAH}$ is often associated with excessive androgen levels. Adrenal androgens directly inhibit aromatase activity in granulosa cells of the ovary, thus indirectly hindering foliculogenesis. The high androgen levels result in gonadotropin-releasing hormone $(\mathrm{GnRH})$, inhibition, leading to anovulation $[10,11]$.

Thankfully, with glucocorticoid replacement therapy of patients with classical CAH, females mature into adults, so the focus has shifted to infertility treatment [2]. These patients suffer not only from salt wasting, they also have concomitant excessive androgens, excessive progesterone, post-reconstructive surgery states, PCOS, ovarian adrenal rest tumors and various psychosexual factors [1,5,11-14].

In our study, we presumed that the mutations c.290-13A/C $>$ G, p.I172N, p.P30L and p.V281L in the CYP21A2 gene are associated with infertility and influence clinical and laboratory parameters of women with UFP. For this purpose, we compared genetic profiles of couples with UFP with genetic profiles of healthy controls (HCs). Furthermore, we have also analyzed associations between mutations in the CYP21A2 gene and various clinical and laboratory parameters.

\section{MATERIALS AND METHODS}

Probands. Our study was a retrospective study and included 838 probands representing two different groups: couples with UFP and HCs. Couples with UFP ( $n=638,319$ females and 319 males), were referred to our laboratory from the Department of Reproductive Medicine and Gynecologic Endocrinology, University Clinical Centre Maribor, Maribor, Slovenia, for routine karyotyping. At the time of enrollment in the study, all probands were childless as a couple and had not undergone $\mathrm{CAH}$ diagnosis. Clinical data of interest was extracted from a questionnaire designed for the needs of the study and existing medical records collected between 2005 and 2012. The HCs $(n=200,100$ females and 100 males) were blood donors with an unremarkable reproductive history, who were recruited through the Department of Transfusiology, University Clinical Centre Maribor, Maribor, Slovenia.

All samples were from individuals of Caucasian origin who were residents of different geographical areas of Slovenia. Informed consent was obtained from all participating individuals and ethical approval was granted prior to conducting the study.

Clinical and Hormonal Investigations. For female probands, the following clinical and biochemical parameters were determined: the concentration of prolactin in serum $(\mathrm{nmol} / \mathrm{L})$, the concentration of dihydroepiandrosterone in serum $(\mathrm{nmol} / \mathrm{L})$, the concentration of free testosterone in serum $(\mathrm{nmol} / \mathrm{L})$, the concentration of testosterone in serum $(\mathrm{nmol} / \mathrm{L})$, concentration of Anti-Muller hormone levels in serum $(\mathrm{nmol} / \mathrm{L})$, body mass index (BMI), the presence of a thyroid disease, the presence of an autoimmune disease, the presence of PCOS.

The follicular phase of the menstrual cycle was determined: the concentration of follicle-stimulating hormone in serum $(\mathrm{nmol} / \mathrm{L})$, the concentration of luteinizing hormone in serum $(\mathrm{nmol} / \mathrm{L})$, the concentration of 1,2-estradiol in the serum $(\mathrm{nmol} / \mathrm{L})$. In the luteal phase of the menstrual cycle, the concentration of progesterone in the serum $(\mathrm{nmol} / \mathrm{L})$ was determined. Basic laboratory parameters of female probands are given in Table 1.

DNA Extraction and Analysis. Peripheral venous blood was collected in standard collection vacutainers containing EDTA as anticoagulant. Genomic DNA was extracted from blood leukocytes 
with a simple salting-out method [15]. All DNA samples were screened for the four most common mutations (p.P30L in exon 1, c.290-13A/ C $>\mathrm{G}$ in intron 2, p.I172N in exon 4 and p.V281L in exon 7) in the CYP21A2 gene using allele-specific polymerase chain reaction (PCR). Four PCR reactions were performed per sample with the Multiplex PCR Kit (Cat. \#206143; Qiagen GmbH, Hilden, Germany). The mix included $1 \mathrm{X}$ master mix, $1 \mu \mathrm{M}$ of each primer and $50 \mathrm{ng}$ of genomic DNA. In reaction 1, the p.P30L mutation in exon 1 was detected with CAH-30LT-P-F (5'-AAG CTC CGG AGC CTC CAC CTA CT-3') and CAH-I1-A-R1 (5'-AGC ATA GCAAGAACC CAT CTG TT-3'). In reaction 2, the c. $290-13 \mathrm{~A} / \mathrm{C}>\mathrm{G}$ mutation in intron 2 was detected with CAH-I2-A2-F (5'-CTA ACT ACA TAT CTG GTG GGG AGA AAG C-3') and CAH-In2-M-GR (5'-CAG CTT GTC TGC AGG AGG CGC-3'). In reaction 3 , the p.I172N mutation in exon 4 was detected with CAH-172NA-F (5'-TCT CTC CTC ACC TGC AGC ATG AA-3') and CAH-I172N-ARL (5'-TTC ATG TCG TCC TGC CAG AAA AGC AG-3'). In reaction 4, the p.V281L mutation in exon 7 was detected with CAH-I6-A-F (5'-CAG CAC AAG GTG GGG ACT GGA C-3'). The annealing temperature was $63{ }^{\circ} \mathrm{C}$ in 30 amplification cycles. Successful PCR amplification was confirmed by electrophoresis on $3.0 \%$ agarose gel, stained with SYBR Green I, and photographed for documentation and mutation scoring.

Statistical Analyses. For statistical analysis, the Statistical Package for the Social Science (SPSS), version 21 software program (IBM Corporation, Armonk, NY, USA), was used. Comparison between the means was done by non parametric tests. The results were expressed as an arithmetic mean \pm standard deviation (SD). The relations between variables were analyzed by the analysis of variance (ANOVA) test. The distribution of the mutations was compared using the $\chi^{2}$ test; $p \leq 0.05$ was considered statistically significant.

\section{RESULTS}

We analyzed 319 couples, a total of 638 individuals (average age 32.9 years, median age 33 years), 319 females (average and median age 32 years, range 21-44 years) and 319 males (average age 33.8 years, median age 34 years, range $23-44$ years). The control
Table 1. Ages, mean ages and age ranges of the male and female probands.

\begin{tabular}{|l|c|c|c|}
\hline & Total & Males & Females \\
\hline$n$ (probands) & 638 & 319 & 319 \\
\hline Mean age & 32.9 & 33.8 & 32.0 \\
\hline Age range (years) & $21-44$ & $23-44$ & $21-44$ \\
\hline
\end{tabular}

Table 2. Number and percentage of female probands with the deviation of laboratory parameters from the reference value and the presence of the clinical indicators.

\begin{tabular}{|l|r|r|}
\hline Parameters/Clinical Indicator & $\boldsymbol{n}$ & $\mathbf{~ \% ~}$ \\
\hline A thyroid disease & 19 & 6.1 \\
Hor & 40 & 12.5 \\
Est & 22 & 6.9 \\
Prog & 3 & 0.9 \\
\hline An autoimmune disease & 6 & 1.9 \\
PCOS & 18 & 5.6 \\
BMI & 44 & 13.8 \\
\hline
\end{tabular}

Hor: deviation of estrogens and/or 17-OHP and/or testosterone in serum; Est: deviation of estrogens in serum; Prog: deviation of 17-OHP in serum. Autoimune disease: celiac disease; Chron's disease; psoriasis; rheumatoid arthritis; lupus and ulcerative colitis. PCOS: polycystic ovary syndrome; BMI: body mass index.

group included 200 healthy blood donors (average and median age 43 years), 100 females (average and median age 42 years, range 27-66 years) and 100 males (average and median age 44 years, range 2171 years) (Table 1$)$.

For female probands, significant clinical parameters, biochemical parameters and the simultaneous presence of: a thyroid disease, increased BMI, an autoimmune disease, PCOS, conditions related to the concentration of sex hormones and conditions related to the concentration of progesterone, were determined. Number and proportions of female probands with the deviation of laboratory parameters from the reference value and the presence of the clinical indicators are presented in Table 2.

From Table 2, we can see that in the study group the proportion of females with the irregularities within the concentration of hormones (12.5\%) stand out. At the same time, the smallest proportion belongs to the females with the deviation of 17-OHP in serum $(0.9 \%)$. The c.290-13A/ C $>$ G, p.I172N, p.P30L and $p . V 281 \mathrm{~L}$ mutation frequencies were compared between probands and controls. There were no significant differences in mutation frequencies for all 
four mutations $\left(\chi^{2}=2.167, p=0.141\right)$. Results are presented in Table 3.

Additionally, the c.290-13A/C $>$ G, p.I172N, p.P30L and p.V281L mutation frequencies were compared between male and female probands. There were no significant differences in mutation frequencies for all four mutations $\left(\chi^{2}=2.254, p=0.324\right)$ (Table 4).

The possible impact of most common mutations in the CYP21A2 gene on clinical and laboratory parameters were determined by the ANOVA test for the whole group and separately, only for female individuals. The ANOVA test showed no effect of mutations on laboratory parameters for the female group of individuals. For the analysis of the impact of mutations on the presence of clinical parameters, association analysis for the statistical processing of using data was used (Table 5).

We found a statistically significant association between clinical indicator for irregularities within the concentration of hormones and the p.V281L mutation $\left(\chi^{2}=6.997, p=0.008\right)$ (see Table 5). We have also found a statistically significant association between the PCOS and the p.V281L mutation $\left(\chi^{2}=16.775\right.$, $p=0.000$ ) (see Table 5). In the case of other clinical indicators, we did not find a statistically significant correlation with the studied mutations.

Table 3. The c.290-13A/C > G, p.I172N, p.P30L and p.V281L mutation frequencies in couples with unexplained fertility problems and controls.

\begin{tabular}{|l|c|c|c|c|}
\hline Mutations & Probands $(\boldsymbol{n}=\mathbf{6 3 8}) \mathbf{( \% )}$ & Controls $(\boldsymbol{n}=\mathbf{2 0 0}) \mathbf{( \% )}$ & $\chi^{2}$ & $p$ Value \\
\hline c.290-13A/C $>\mathrm{G}$ & $4(0.6)$ & $1(0.5)$ & 0.043 & 0.836 \\
\hline p.I172N & $4(0.6)$ & $3(1.5)$ & 1.389 & 0.239 \\
\hline p.P30L & $0(0.0)$ & $1(0.5)$ & 3.183 & 0.074 \\
\hline p.V281L & $1(0.2)$ & $1(0.5)$ & 0.749 & 0.387 \\
\hline Total & $9(1.4)$ & $6(3.0)$ & 2.167 & 0.141 \\
\hline
\end{tabular}

Table 4. Number and percentage of mutations discovered in the male and females probands.

\begin{tabular}{|l|c|c|c|c|c|c|}
\hline & \multicolumn{2}{|c|}{ Males } & \multicolumn{2}{c|}{ Females } & $\chi^{2}$ & $p$ Value \\
\hline Mutations & $n$ & $\%$ & $n$ & $\%$ & & 0.979 \\
\hline c.290-13A/C>G & 2 & 0.6 & 2 & 0.6 & 0.043 & 0.499 \\
\hline p.I172N & 2 & 0.6 & 2 & 0.6 & 1.389 & 0.000 \\
\hline p.P30L & 0 & 0.0 & 0 & 0.0 & $\mathbf{0 . 0 0 0}$ & 0.495 \\
\hline p.V281L & 1 & 0.3 & 0 & 0.0 & 1.405 & 0.324 \\
\hline Total & 5 & 1.6 & 4 & 1.3 & 2.254 & \\
\hline
\end{tabular}

Table 5. Comparison of clinical parameters of the entire group of female probands with the c.290-13A/C >G, p.I172N, p.P30L and p.V281L mutations and female probands without the c.290-13A/C $>$ G, p.I172N, p.P30L and p.V281L mutations.

\begin{tabular}{|l|c|c|c|c|}
\hline Clinical Parameters & $\begin{array}{c}\mathbf{c . 2 9 0 - 1 3 A} / \mathbf{C}>\mathbf{G} \\
\left(\chi^{2} ; \boldsymbol{p} \text { value }\right)\end{array}$ & $\begin{array}{c}\mathbf{p . I 1 7 2 N} \\
\left(\chi^{2} ; \boldsymbol{p} \text { value }\right)\end{array}$ & $\begin{array}{c}\mathbf{p . P 3 0 L} \\
\left(\chi^{2} ; \boldsymbol{p} \text { value }\right)\end{array}$ & $\begin{array}{c}\mathbf{p . V 2 8 1 L} \\
\left(\chi^{2} ; \boldsymbol{p} \text { value }\right)\end{array}$ \\
\hline A thyroid disease & $0.257 ; 0.613$ & $0.257 ; 0.613$ & $-;-$ & $0.064 ; 0.801$ \\
\hline Hor & $0.581 ; 0.446$ & $0.581 ; 0.446$ & $-;-$ & $\mathbf{6 . 9 9 7 ; 0 . 0 0 8}$ \\
\hline Est & $0.300 ; 0.584$ & $0.300 ; 0.584$ & $-;-$ & $0.074 ; 0.785$ \\
\hline Prog & $0.038 ; 0.845$ & $0.038 ; 0.845$ & $-;-$ & $0.010 ; 0.922$ \\
\hline An autoimmune disease & $0.078 ; 0.781$ & $0.078 ; 0.781$ & $-;-$ & $0.019 ; 0.890$ \\
\hline PCOS & $0.242 ; 0.623$ & $0.242 ; 0.623$ & $-;-$ & $\mathbf{1 6 . 7 7 5 ; 0 . 0 0 0}$ \\
\hline BMI & $0.648 ; 0.421$ & $0.648 ; 0.421$ & $-;-$ & $0.161 ; 0.689$ \\
\hline
\end{tabular}

Hor: deviation of estrogens and/or 17-OHP and/or testosterone in serum; Est: deviation of estrogens in serum; Prog: deviation of 17-OHP progesterone in serum. Autoimune diseases: celiac disease; Chron's disease; psoriasis; rheumatoid arthritis; lupus and ulcerative colitis. PCOS: polycystic ovary syndrome; BMI: body mass index. 


\section{DISCUSSION}

In our research, we determined the frequency of the c.290-13A/C > G, p.I172N, p.P30L and p.V281 mutations in couples with conceiving problems comparing them with a healthy control group. We did not observe any statistical differences between frequency of heterozygous carriers in infertile couples and HCs. Although we did not find any statistically important association, we cannot exclude the importance of the aforementioned mutations in infertility. We attribute it to an insufficient number of test subjects and controls. Also, we cannot draw an indefinite conclusion, as the presence of mutations in the CYP21A2 gene may be associated with infertility [16]. It is also important to point out that in samples without the c.290-13A/C $>$ G, p.I172N, p.P30L and p.V281 mutations, we cannot exclude the presence of other mutation variants in the CYP21A2 gene [17].

In female test subjects, we examined the hormonal profiles during stages of the menstrual cycle and determined concomitant diagnosed illnesses from available medical documentation. We did not find any statistically significant association between hormonal deviations, concomitant illnesses and mutation frequency. However, we can conclude that the presence of a single mutation in the CYP21A2 gene does not distinctively affect the hormonal status $[9,18]$.

In general, fertility in people with $\mathrm{CAH}$ ranges from normal to severely impaired, as Reichman et al. [19] found that most CAH patients encountered fertility issues. In addition, these patients had less successful natural conceptions with more patients reporting spontaneous abortions. Similarly, Reichman et al. [19] found the frequency of successful conceptions is inversely proportional to the severity of mutations. To explain, females with an evidently more significant structural anomaly encountered more difficulties in conception $[7,8,19]$. Moreover, structurally milder mutations did not significantly affect fertility.

Çakir et al. [20] found that males with CAH have an evident diminished reproductive capability due to the presence of hipogonadotropic hipogonadism and consequently testicular adrenal rest tumors (TART). The latter, being more common, have adrenocorticotropic hormone (ACTH) and angiotensin II receptors and they synthesize similar steroid hormones as the adrenal glands. Permanent localized high steroid concentration may in turn damage the testes $[16,20]$.
Peritubular testicular fibrosis results in impaired spermatogenesis [21]. In addition, the size of TART is inversely proportional to testosterone production and sperm ejaculation count [22].

We also studied the association between mutations in CAH and most frequently found concomitant illnesses. We did not find any association between female test subjects and the frequency of associated illnesses. Deckx et al. [23] found estrogens and progesterins to have immunomodulatory properties. In addition, Gleicher et al. [24] found that infertile females not only possess a diminished ovarian reserve but also serological profiles associated with autoimmune diseases. Moreover, he implicates an existence of an androgen derived cofactor, responsible for immunologic disorders [24]. In our study, we did not find any statistically significant association between the presence of a mutation and the level of testosterone in female subjects.

The CYP21A2, RP, C4 and TNX genes are structurally adjacent, thus forming a genetic module RCCX complex. Olsson and Holmdahl [25] determined that $\mathrm{CAH}$ is closely associated with autoimmunity. Chen et al. [26] found that a mutation in the CYP21A2 gene results not only in 21-OH deficiency but also in a variable copy count of the $C 4$ gene. To clarify, the $C 4$ gene encodes a homonymous protein, involved in classic complement activation [26]. In our study, we did not find a statistically significant association between autoimmunity and our studied mutations.

Thyroid disorders are closely associated with infertility. They not only affect female fertility but also hinder most of the human organs [27,28]. Sinha et al. [29] found that in thyrotoxicosis there is an increase of all sex hormones and their plasma binding proteins. As mentioned, excess estrogens hamper conception and pregnancy [2,10, 29]. Mansourian [30] and Mnif et al. [11] found that pathologic hormonal profiles of women with hyper- and hypothyroidism often result in abortions, low birth weight and premature labor. In our study, we did not find any association between mutations in the CYP21A2 gene and the presence of thyroid disease.

On the other hand, we found an association between the p.V281L mutation in the CYP21A2 gene and a marker indicating any hormonal deviance $(p=$ $0.008)$. Next, we also found an association between the p.V281L mutation in the CYP21A2 gene and the 
frequency of $\operatorname{PCOS}(p=0.000)$. Although we found this association, we cannot categorically confirm an actual association due to the small number of enrolled test subjects.

Surprisingly, we did not find a firm association between mutations and deviance in hormonal profiles. Of course, our results do not disprove that the c.290-13A/C>G, p.I172N, p.P30L and p.V281L mutations in the CYP21A2 gene are involved in infertility. Further research is necessary in order to clarify whether $\mathrm{CAH}$ is involved in infertility. According to Montgomery et al. [31], genome-wide association studies (GWAS) represent an evolution in polymorphism, mutation and gene research. Broad population GWAS, using multiple gene markers and extensive clinical information will be important in helping clinicians in not only disease treatment but also in predicting the risk of concomitant disease occurrence [29,31].

Whether it is necessary to enroll all couples diagnosed with infertility in genetic counseling, is still debatable. Many studies confirm the necessity of such a protocol, as there is a confirmed higher incidence of gene mutations among these couples [32]. Conversely, Papanikolaou et al. [33] disagrees with mandatory genetic testing of couples with infertility. He proposed that genetic testing should be executed only upon a valid indication.

In conclusion, does an early diagnosis of $\mathrm{CAH}$ essentially reduce the consequence of $\mathrm{CAH}$ ? Moreover, should we be actively screening the population for mutations in the CYP21A2 gene? To date, in the USA and 40 other countries, screening of CAH is done at birth [34]. The multitude of disease manifestations develop with age, therefore, in order to minimize disease outcomes, many stress the necessity of early detection of CAH $[35,36]$.

\section{ACKNOWLEDGMENTS}

The authors would like to thank the members of the Department of Reproductive Medicine and Gynaecologic Endocrinology of the University Clinical Centre Maribor, Maribor, Slovenia for their helpful contributions to this study.

Declaration of Interest. The authors report no conflicts of interest. The authors alone are responsible for the content and writing of this article.

\section{REFERENCES}

1. Kosova G, Scott NM, Niederberger C, Prins GS, Ober C. Genome-wide association study identifies candidate genes for male fertility traits in humans. Am J Hum Genet. 2012; 90(6): 950-961.

2. Barnhart KT. Early pregnancy failure: Beware of the pitfalls of modern management. Fertil Steril. 2012; 98(5): 1061-1065.

3. Trapp CM, Oberfield SE. Recommendations for treatment of nonclassic congenital adrenal hyperplasia (NCCAH): An update. Steroids. 2012; 77(4): 342-346.

4. Sumida C, Kondoh N, Kurajoh M, Koyama H, Tsutsumi Z, Moriwaki Y, et al. 21-Hydroxylase deficiency associated with male infertility: Report of 2 cases with gene analyses. Intern Med. 2011; 50(12): 1317-1321.

5. Haider S, Islam B, D'Atri V, Sgobba M, Poojari C, Sun L, et al. Structure-phenotype correlations of human CYP21A2 mutations in congenital adrenal hyperplasia. Proc Natl Acad Sci USA. 2013; 110(7): 2605-2610.

6. Finkielstain GP, Chen W, Mehta SP, Fujimura FK, Hanna RM, Van Ryzin C, et al. Comprehensive genetic analysis of 182 unrelated families with congenital adrenal hyperplasia due to 21-hydroxylase deficiency. J Clin Endocrinol Metab. 2011; 96(1): E161-E172.

7. Bidet M, Bellanné Chantelot $\mathrm{C}$, Galand-Portier MB, Golmard JL, Tardy V, Morel Y, et al. Fertility in women with nonclassical congenital adrenal hyperplasia due to 21-hydroxylase deficiency. J Clin Endocrinol Metab. 2010; 95(3): 1182-1190.

8. Belinda G, Vinay D, Moolechery J, Mathew V, Anantharaman R, Ayyar V, et al. Congenital adrenal hyperplasia - Experience from a tertiary centre in South India. Indian J Endocrinol Metab. 2012; 16(2): S385-S386.

9. Nermoen I, Brønstad I, Fougner KJ, Svartberg J, Øksnes M, Husebye ES, et al. Genetic, anthropometric and metabolic features of adult Norwegian patients with 21-hydroxylase deficiency. Eur J Endocrinol. 2012; 167(4): 507-516.

10. Knowles RL, Khalid JM, Oerton JM, Hindmarsh PC, Kelnar CJ, Dezateux C. Late clinical pre- 
sentation of congenital adrenal hyperplasia in older children: findings from national paediatric surveillance. Arch Dis Child. 2014; 99(1): 30-34.

11. Mnif MF, Kamoun M, Kacem FH, MnifF, Charfi $\mathrm{N}$, Naceur BB, et al. Reproductive outcomes of female patients with congenital adrenal hyperplasia due to 21-hydroxylase defi ciency. Indian J Endocrinol Metab. 2013; 17(5): 790-793.

12. Falhammar H, Nyström HF, Ekström U, Granberg S, Wedell A, Thorén M. Fertility, sexuality and testicular adrenal rest tumors in adult males with congenital adrenal hyperplasia. Eur J Endocrinol. 2012; 166(3): 441-449.

13. Hall JE, Guyton AC. Guyton and Hall Textbook of Medical Physiology. Philadelphia, PA: Saunders/Elsevier, 2011.

14. Borko E, Takač I, But I, Gorišek B, Kralj B. Gynecology, 1st ed. Maribor, Slovenia: High School of Nursing Press, 2006.

15. Miller SA, Dykes DD, Polesky HF. A simple salting out procedure for extracting DNA from human nucleated cells. Nucleic Acids Res. 1988; 16(3): 1215.

16. New MI, Abraham M, Gonzalez B, Dumic M, Razzaghy-Azar M, Chitayat D, et al. Genotypephenotype correlation in 1,507 families with congenital adrenal hyperplasia owing to 21-hydroxylase deficiency. Proc Natl Acad Sci USA. 2013; 110(7): 2611-2616.

17. Dolzan V, Stopar-Obreza M, Zerjav-Tansek M, Breskvar K, Krzisnik C, Battelino T. Mutational spectrum of congenital adrenal hyperplasia in Slovenian patients: A novel Ala15Thr mutation and Pro30Leu within a larger gene conversion associated with a severe form of the disease. Eur J Endocrinol. 2003; 149(2): 137-144.

18. Krone N, Rose I, Willis D, Hodson J, Wild SH, Doherty EJ, et al. Genotype-phenotype correlation in 153 adult patients with congenital adrenal hyperplasia due to 21-hydroxylase deficiency: Analysis of the United Kingdom Congenital adrenal Hyperplasia Adult Study Executive (CaHASE) cohort. J Clin Endocronol Metab. 2013; 98(2): 346-354.

19. Reichman DE, White PC, New MI, Rosenwaks Z. Fertility in patients with congenital adrenal hyperplasia. Fertil Steril. 2014; 101(2): 301-309.
20. Çakir ED, Mutlu FS, Eren E, Paşa AO, Sağlam $\mathrm{H}$, Tarim O. Testicular adrenal rest tumors in patients with congenital adrenal hyperplasia. J Clin Res Pediatr Endocrinol. 2012; 4(2): 94-100.

21. Claahsen-van der Grinten HL, Otten BJ, Hermus AR, Sweep FC, Hulsbergen-van de Kaa CA. Testicular adrenal rest tumors in patients with congenital adrenal hyperplasia can cause severe testicular damage. Fertil Steril. 2008; 89(3): 597-601.

22. Claahsen-van der Grinten HL, Otten BJ, Sweep FC, Hermus AR. Repeated successful induction of fertility after replacing hydrocortisone with dexamethasone in a patient with congenital adrenal hyperplasia and testicular adrenal rest tumors. Fertil Steril. 2007; 88(3): 705-708.

23. Deckx N, Lee WP, Berneman ZN, Cools N. Neuro-endocrine immunoregulation in multiple sclerosis. Clin Dev Immunol. 2013; 2013: 705232. doi: 10.1155/2013/ 705232 .

24. Gleicher N, Weghofer A, Kushnir VA, ShohatTal A, Lazzaroni E, Lee HJ. Is androgen production in association with immune system activation potential evidence for existence of a functional adrenal/ovarian autoimmune system in women? Reprod Biol Endocrinol. 2013; 11: 58. doi: 10/1186/1477-11-58.

25. Olsson LM, Holmdahl R. Copy number variation in autoimmunity-importance hidden in complexity? Eur J Immunol. 2012; 42(8): 1969-1976.

26. Chen W, Xu Z, Nishitani M, Van Ryzin C, McDonnell NB, Merke DP. Complement component 4 copy number variation and CYP21A2 genotype associations in patients with congenital adrenal hyperplasia due to 21-hydroxylase deficiency. Hum Genet. 2012; 131(12): 1889-1894.

27. Stone MB, Stanford JB, Lyon JL, VanDerslice JA, Alder SC. Childhood thyroid radioiodine exposure and subsequent infertility in the intermountain fallout cohort. Environ Health Perspect. 2013; 121(1): 79-84.

28. Chang DL, Pearce EN. Screening for maternal thyroid dysfunction in pregnancy: A review of the clinical evidence and current guidelines. J Thyroid Res. 2013; 2013: 851326. doi: $10.1155 / 2013 / 851326$.

29. Sinha U, Sinharay K, Saha S, Longkumer TA, Baul SN, et al. Thyroid disorders in polycystic 
ovarian syndrome subjects: A tertiary hospital based cross-sectional study from Eastern India. Indian J Endocrinol Metab. 2013; 17(2): 304-309.

30. Mansourian AR. Female reproduction physiology adversely manipulated by thyroid disorders: A review of literature. Pak J Biol Sci. 2013; 16(3):112-120.

31. Montgomery GW, Zondervan KT, Nyholt DR. The future for genetic studies in reproduction. Mol Hum Reprod. 2014; 20(1): 1-14.

32. Esteves SC. A clinical appraisal of the genetic basis in unexplained male infertility. J Hum Reprod Sci. 2013; 6(3): 176-182.

33. Papanikolaou EG, Vernaeve V, Kolibianakis E, Assche EV, Bonduelle M, Liebaers I, et al. Is chromosome analysis mandatory in the initial investigation of norm-ovulatory women seeking infertility treatment? Hum Reprod. 2005; 20(10): 2899-2903.
34. Pass KA, Neto EC. Update: Newborn screening for endocrinopathies. Endocrinol Metab Clin North Am. 2009; 38(4): 827-837.

35. Gidlöf S, Wedell A, Guthenberg C, von Döbeln U, Nordenström A. Nationwide neonatal screening for congenital adrenal hyperplasia in Sweden: A 26-year longitudinal prospective population-based study. JAMA Pediatr 2014; 168(6): 567-574.

36. Knowles RL, Khalid JM, Oerton JM, Hindmarsh PC, Kelnar CJ, Dezateux C. Late clinical presentation of congenital adrenal hyperplasia in older children: Findings from national paediatric surveillance. Arch Dis Child. 2014; 99(1): 30-34. 